\title{
Creation of a Scholars Program in Dental Leadership (SPDL) for Dental and Dental Hygiene Students
}

\author{
Russell S. Taichman, D.M.D., D.M.Sc.; Thomas G. Green, Ph.D.; \\ Peter J. Polverini, D.D.S., D.M.Sc.
}

Abstract: There is a great need for leaders in the dental profession. As technological advances make our world smaller and our lives faster and more complex, we as a profession face challenges and opportunities that are evolving. Many of the changes in the scope and mode of practice will require new and different approaches. Meeting these challenges will require changes in how we as dental professionals do business; interact with our patients, other stakeholders, and health care providers; and educate our future colleagues. The purposeful incorporation of leadership education into dental and dental hygiene curricula represents an important departure from existing paradigms - but will help prepare our students to address these challenges. This article provides an overview of the development of a Scholars Program in Dental Leadership (SPDL) at the University of Michigan School of Dentistry. Our aim for the program is to create a learning environment that fosters leadership development, so that students are prepared and motivated to assume leadership positions in the profession and their communities.

Dr. Taichman is Director of the University of Michigan Scholars Program in Dental Leadership and Professor, Department of Periodontics and Oral Medicine, School of Dentistry, University of Michigan; Dr. Green is Director, Curriculum and Instructional Services, Office of Academic Affairs, School of Dentistry, University of Michigan; and Dr. Polverini is with the University of Michigan Scholars Program in Dental Leadership and Dean, School of Dentistry, University of Michigan. Direct correspondence and requests for reprints to Dr. Russell Taichman, Department of Periodontics and Oral Medicine, School of Dentistry, University of Michigan, 1011 North University Avenue, Ann Arbor, MI 48109-1078; 734-764-9952 phone; 734-763-5503 fax; rtaich@umich.edu.

Keywords: leadership, dental education, faculty development, leading change

Submitted for publication 2/17/09; accepted 6/26/09

$\mathrm{D}$ ental education was said to be at a crossroads fourteen years ago, and in most ways it still is. ${ }^{1}$ There is a shortage of dental leaders willing to challenge existing paradigms. Few students express a desire to explore the rich intellectual and service life that our profession has to offer. Fewer still are willing to join the ranks of scholars and community leaders necessary for our profession to flourish as a vibrant and evidence-based discipline in the twenty-first century. ${ }^{2}$ If these trends are to change, we must challenge existing cultural norms in order to prepare students to have an impact on the future of dentistry and its role in health care. This can be accomplished if dental schools are willing to expand their academic mission and offer opportunities in leadership development. ${ }^{3}$

Developing leadership skills entails many facets of life. Characteristics of a leader include, but are not limited to, being someone who is a strategic thinker; someone who comes to the table with good ideas and is willing to shoulder the burden of implementation; someone with a desire to seek the truth and a willingness to serve as a change agent; someone who serves the organization above self and is able to articulate a shared vision; someone with a willingness to address and manage challenges and conflicts in a positive manner; and someone with honesty and integrity. In dentistry, leadership would include running a practice effectively, but a willingness to serve as a change agent and participate in the broader social, political, and economic environment that affects our profession is also essential. Many areas outside of dentistry (the military, the airline industry, other parts of the corporate world, etc.) have begun to identify leadership qualities and are developing training methods to enhance them for members of their professions.

While leadership training is becoming more common in other areas, it is still in its infancy in dentistry and other health care professions. However, 
a recent study by Victoroff et al. found that dental students overwhelmingly view leadership as a part of their profession and would be willing to participate in leadership training programs within their institutions. ${ }^{4}$ Likewise, in 2000 nearly 70 percent of responding dental school deans reported that leadership training was the most crucial factor in preparing to become a dean. ${ }^{5}$ In fact, this area of study and experience was perceived by the respondents in that study to be more important than the ability to teach dentistry, knowledge of budget and finance, and conducting research.

Recently, an eleven-week program was developed by the School of Dentistry at the University of Southern California. ${ }^{6}$ This program combines many of the traditional industry-wide aspects of leadership training including communication styles and listening, people management, creating and leading a team, building coalitions, conflict management, and fiscal and budget management. But what should leadership training in dentistry involve, in the context of a national need for dental leaders? Should dentistry be looking exclusively to business schools for leadership content? Is management training leadership training? Is research experience leadership training in and of itself? We assert that the need is much greater and goes beyond existing practices and that dental schools must develop their own curricula.

The vision of the University of Michigan's Scholars Program in Dental Leadership (UM-SPDL) is to empower dental and dental hygiene students to envision and promote cultural changes in the realm of dentistry. Our mission is to bring together the very best, brightest, and hardest working students with diverse backgrounds and to center their talents on a shared goal of developing leadership skills. Through combined student-faculty efforts, we believe that an environment can be created that will serve all segments of our profession.

The objectives of the UM-SPDL are as follows:

1. to encourage critical thinking in leadership for dentistry through the development and implementation of new educational experiences with an emphasis on leadership;

2. to serve the dental community by functioning as a laboratory for educational innovation;

3 . to cultivate exploration and creativity in predoctoral dental and dental hygiene students through independent study and supervised research;

4. to maximize the dental school's position of leadership in dental education by offering the program as a model/subject/resource for scholarly and intellectual enrichment; and

5. to advance the dental school's mission through offering a high-quality education to a diverse student population and to assist the university's efforts to recruit highly qualified students for all its divisions.

The UM-SPDL represents an important departure from the existing dental school curriculum. Intensive and focused experiences in leadership development are provided that extend beyond the traditional curriculum. UM-SPDL students are those willing to wrestle with global issues facing the dental profession - topics such as access to care, challenges and opportunities for the profession related to universal health care, how best to integrate dentistry into the spectrum of health care delivery, funding professional education, incorporation of new paradigms in research and business that have yet to fully impact the profession, and how to best position dental education both within the university and among other professions. This article describes the program's development and early stages.

\section{Development of the UM-SPDL}

The development of an SPDL at the University of Michigan School of Dentistry began in 2004 with the formation of a program design committee with representatives from the faculty, predoctoral dental students, and predental students. The committee solicited comments from all segments of our faculty and predoctoral student body.

Central points considered during the design phase of the program were as follows:

- What would be the mission of the program?

- What should be the core competencies?

- What should the structure be?

- Who would provide the curriculum content, and how would the program fit within the framework of the existing dental and dental hygiene curricula?

- What size program was desirable?

- How would students be recruited, and how would candidates be evaluated for enrollment?

- Which students would be targeted for inclusion?

- Would there be incentives for enrollment?

The program was conceptualized to encompass all four years of the dental and dental hygiene curricula, providing sufficient time for adult and group 
learning and the development of capstone projects targeting the interests of the participants. The SPDL was designed to "wrap around" the existing curricula, so program events would occur after regular classes ended. In program design, emphasis was placed on tailoring the content to the participants to ensure maximum engagement. The initial core competencies included leadership, continuous learning, problem solving, strategic thinking, and communicating. ${ }^{7}$ Initially, partnerships with various other colleges on our campus were sought to provide the curriculum content. However, when we considered differences in the target audience, ideas pertaining to potential launch dates, competencies, and costs, it was felt that the dental school should develop its own program.

Based upon a number of logistical parameters, the ideal target size of the UM-SPDL for the first year was determined to be approximately twenty students, which was envisioned to grow by five to ten students per year. An emphasis was placed on recruiting incoming freshman dental and dental hygiene students. The rationale behind targeting early students was a belief that these individuals would be the greatest risk takers since they had not yet experienced the traditional dental or dental hygiene curriculum and might be more open to new experiences than those already in school. Program application materials were sent out in the spring to current students and new students who had just received notification of acceptance and were due prior to the start of the academic year.

\section{Launching the UM-SPDL}

In May 2006, we sent SPDL recruitment materials to the first cohort of students. The selection process took place in July 2007 and resulted in twenty students (ten first-year, six second-year, and two third-year dental students and two third-year dental hygiene students). Selection was based upon the students' letters of recommendation and essays. In their essays, applicants were asked to discuss their experiences as leaders in their communities, their thoughts on the program's core competencies, and the sort of projects they wished to develop in the program. Applications were reviewed by the UM-SPDL Program Committee, and participants were selected based upon the following criteria: the student's desire to develop as a leader, prior successful leadership experiences, interest in leadership, and communication skills. In addition, the committee sought out individuals who were interested in work- ing collaboratively and willing and able to commit to the added responsibility.

In late August 2006, participants in the UMSPDL met for the first time for a kick-off event. An off-site opening banquet was held with an evening address on leadership by Dr. Richard W. Valachovic, executive director of the American Dental Education Association. This was followed by a full day of activities at the Challenge Program at the University of Michigan, an activity-based program that uses a highly interactive and experiential approach to teambuilding and other aspects of organizational development. From September 2006 to April 2007, the UM-SPDL participants met monthly to learn the crucial skills needed for any leadership position. Topics such as personality assessment, conflict resolution, communication, public speaking, biodontics, ${ }^{8}$ and career planning were presented in a way that was both engaging and educational.

Some changes were made in the program in subsequent years. After that initial year, students have invited a number of highly respected individuals from academic, commercial, and legislative organizations to be speakers for the program. In instances in which the speaker would be of interest to a broader audience, the program was opened to the entire dental school community. The kick-off events in the second and third years, like the first, began with a Friday evening session, but incorporated a split Saturday session in which the students and faculty members donated their time and labor at local nonprofit organizations (Perry Nursery School and the Salvation Army in Ann Arbor) and the university's Challenge Program. This split day appears to work well as it keeps events moving and provides opportunities for interactions among faculty, students, and members of the community from the start of the program.

After the first year, students have taken more ownership of the development of each year's program. They defined a new operational structure that offers ways for students to take individual initiative in applying their new skill set, while working collectively towards common goals. A constitution, executive, and student-run committees were established to facilitate the logistical and planning operations of the SPDL. In early 2007, the students compiled a working list of competencies in which they were interested and began the initial phases of designing a program curriculum focused on major issues in dentistry. Participants joined teams dedicated to specific projects within the general field of dentistry. To monitor, maintain, and facilitate team interactions, faculty 
mentors who were initially assigned to individual SPDL students were reassigned to project teams. This focus on teams provides better mentorship for the newer participants and facilitates the development of capstone projects.

\section{The Future of the SPDL}

The UM-SPDL represents a long-term commitment by our university and school to promote leadership in dentistry. We believe that a specific focus on leadership is an essential component of dental education that is missing from many schools' curricula. In many ways, this program has been developed on the principle that you can "build the bridge as you walk on it," and many opportunities have emerged or been created after the program was launched. First and foremost, the program has created opportunities for student-faculty engagement that is in many ways unique. The UM-SPDL provides an informal setting for collegial discussions between students and faculty members that is not available in the classroom or clinical setting. In this respect, many of the institutional barriers to learning can be overcome. The value of this aspect of an SPDL program cannot be overstated. Far too often we have heard that dental graduates are jaded and feel disenfranchised from the very institution from which they graduated. Part of this feeling is likely to emerge from views that, as students, they were unequal partners in the educational process. Preliminary and early evaluations of our SPDL students suggest that they indeed develop a feeling of ownership of the program. They also feel that faculty members are responsive to their needs, listen to them, and treat them as junior colleagues in the development of the program. In fact, many students feel that the faculty have much to learn from them, which in many ways we do, as many of them come to the SPDL with a range of leadership experiences that are both substantial and unique. These experiences lend both diversity and value to our program by bringing in ideas for content and partnerships that have been among the most fulfilling faculty-student interactions we have experienced. The full impact of the program will not be known for years, but clearly it will be important to track the experiences of SPDL participants in the future.

The SPDL also provides a novel opportunity for scholarship. For example, some students in the SPDL published a report on a big sister event they developed as part of an activity aimed at professional commu- nity-building and collaboration in dental hygiene. ${ }^{10}$ In another project, some students conducted a small trial to evaluate dental students' ability to recognize and manage a medical emergency and published the results. ${ }^{11}$ This project has already contributed to enhanced curricular training in medical emergencies for students, faculty, and staff. The SPDL is thus leading to tangible results by providing opportunities and support for student and faculty scholarship, including work in areas not necessarily recognized as having the potential for viable research projects in the past and among individuals who do not have clinical programs or laboratories for testing new ideas.

A scholars program in dental leadership that provides opportunities for student teaching and exploration may also serve as a vehicle for addressing faculty shortages. ${ }^{12,13}$ Since the vast majority of dental and dental hygiene students are not entering the profession with the intent to become faculty members, exposure to faculty mentors and a climate that suggests their interests can be incorporated into scholarship within the realm of oral health sends a message to students that is very different from the one they receive as part of their education to become practitioners. We believe that this exposure may stimulate students to consider career paths that they may not have otherwise been aware of.

Furthermore, the SPDL can serve as a venue for interdisciplinary collaboration and an incubator for educational reform. Several students in our program are working to establish residencies and externships with other academic units on campus and institutions abroad. There are also possibilities for alumni and individuals who traditionally do not participate in dental and dental hygiene education to come together to mentor our students. To address this, we are currently in the process of establishing a "Dean's Faculty" for the UM-SPDL. This new faculty is intended to include individuals with outstanding skills and knowledge to empower our scholars to put theory into action. Dean's Faculty members may include individuals who are willing to contribute to students' education through volunteer activities and may serve as a networking structure to establish collaborations.

\section{Conclusions}

Now, perhaps more than at any other time, there is a need for great leaders in dentistry and dental hygiene. As technological advances make our world 
smaller and our lives faster and more complex, the oral health profession faces challenges and opportunities that are constantly evolving. Changes in the scope and mode of practice will require new and different approaches. Meeting these needs requires changes in how we do business, interact with our patients and other health care providers, and educate our future colleagues. It is certain that oral health research will produce new diagnostic and therapeutic options for our patients, while issues pertaining to public health, ways to deliver care and access information, ethical dilemmas, faculty shortages, and changing market forces will continue to affect our profession. But in these challenges there will be opportunities to break new ground to improve oral health and to improve the stature of the profession. It is here that our focus must remain. A student leadership program provides a novel educational milieu in which discussions on these issues can occur and students can be engaged in broader concerns outside but essential to the usual realm of dental education. It is here that we all must start.

\section{Acknowledgments}

The authors would like to thank the SPDL organizing committee members (Drs. R. Eber, J.N. Kolling, D.J. Chiego Jr., G.E. Gerstner, J.C. Fenno, J.C. Hamilton, J.E. Nor, C.A. Murdok-Kinch, A. Kim, and D. Kager of the University of Michigan); S.G. Gong (University of Toronto); H.M. Pinsky (Delta-Northwest Airlines); A.M. Havens (Harvard University); John Swerdlow, Valerie Uzark, and the staff of the Challenge Program at the University of Michigan; Barbara Mulay and Dr. Deborah Orlowsk of the University of Michigan Human Resource Development; Dr. Marilyn Lantz and her staff at the Office of Academic Affairs; and Mrs. K. Romine and Mrs. J. Clark for their logistical support. We would also like to thank the UM-SPDL students, faculty, and mentors for their inspiration and encouragement and their families for sacrifices made on behalf of the program. This project was supported in part with funds from the University of Michigan's Scholars Program in Dental Leadership.

\section{REFERENCES}

1. Field MJ, ed. Dental education at the crossroads: challenges and change. An Institute of Medicine Report. Washington, DC: National Academy Press, 1995.

2. Crain G. Managing change in dental education: is there a method to the madness? J Dent Educ 2008;72(10): 1100-13.

3. Herzberg MC, Griffith LG, Doyle MJ. Driving the future of dental research. J Dent Res 2006;85:486-7.

4. Victoroff KZ, Schneider K, Perry C. Leadership development for dental students: what do students think? J Dent Educ 2008;72(9):982-8.

5. Brundo GC. Preparing to be a dean. J Dent Educ 2000;64(6):430-2.

6. Slavkin HC, Lawrence L. Incorporating leadership knowledge and skills into the dental education community. J Dent Educ 2007;71(6):708-12.

7. National Oceanic and Atmospheric Administration Leadership Competencies. At: http://www.wfm.noaa.gov/pdfs/ LCDP_VI_Call_for_Applications.pdf. Accessed: April 11,2006 .

8. Rossomando EF. Biodontics: dental students as change agents for dental school curricula. Compend Contin Educ Dent 2005;26:578-81.

9. Quinn RE. Building the bridge as you walk on it: a guide for leading change. Hoboken, NJ: Jossey-Bass Publishers, 2004.

10. Straz A, Taylor N. Can we build it? Yes we can! At: www.adha.org/publications/strive/07-2008-strive.htm. Accessed: August 2, 2008.

11. Le TT, Scheller EL, Pinsky HM, Stefanac SJ, Taichman RS. Ability of dental students to deliver oxygen in a medical emergency. J Dent Educ 2009;73(4):499-508.

12. Haden NK, Beemsterboer PL, Weaver RG, Valachovic RW. Dental school faculty shortages increase: an update on future dental school faculty. J Dent Educ 2000;64(9): 657-73.

13. Nunn PJ, Gadbury-Amyot CC, Battrell A, Bruce SI, Hanlon LL, Kaiser C, Purifoy-Seldon B. The current status of allied dental faculty: a survey report. J Dent Educ 2004;68(3):329-44. 